\title{
OESbathy version 1.0: a method for reconstructing ocean bathymetry with generalized continental shelf-slope-rise structures
}

\author{
A. Goswami ${ }^{1, a}$, P. L. Olson ${ }^{1}$, L. A. Hinnov ${ }^{1, b}$, and A. Gnanadesikan ${ }^{1}$ \\ ${ }^{1}$ Department of Earth and Planetary Sciences, Johns Hopkins University, Baltimore, Maryland, USA \\ ${ }^{a}$ now at: Department of Natural Sciences, Northwest Missouri State University, Maryville, Missouri, USA \\ ${ }^{b}$ now at: Department of Atmospheric, Oceanic, and Earth Sciences, George Mason University, Fairfax, Virginia, USA \\ Correspondence to: A. Goswami (arghya.goswami@gmail.com)
}

Received: 12 February 2015 - Published in Geosci. Model Dev. Discuss.: 2 April 2015

Revised: 14 July 2015 - Accepted: 18 July 2015 - Published: 3 September 2015

\begin{abstract}
We present a method for reconstructing global ocean bathymetry that combines a standard plate cooling model for the oceanic lithosphere based on the age of the oceanic crust, global oceanic sediment thicknesses, plus generalized shelf-slope-rise structures calibrated at modern active and passive continental margins. Our motivation is to develop a methodology for reconstructing ocean bathymetry in the geologic past that includes heterogeneous continental margins in addition to abyssal ocean floor. First, the plate cooling model is applied to maps of ocean crustal age to calculate depth to basement. To the depth to basement we add an isostatically adjusted, multicomponent sediment layer constrained by sediment thickness in the modern oceans and marginal seas. A three-parameter continental shelf-slope-rise structure completes the bathymetry reconstruction, extending from the ocean crust to the coastlines. Parameters of the shelf-slope-rise structures at active and passive margins are determined from modern ocean bathymetry at locations where a complete history of seafloor spreading is preserved. This includes the coastal regions of the North, South, and central Atlantic, the Southern Ocean between Australia and Antarctica, and the Pacific Ocean off the west coast of South America. The final products are global maps at $0.1^{\circ} \times 0.1^{\circ}$ resolution of depth to basement, ocean bathymetry with an isostatically adjusted multicomponent sediment layer, and ocean bathymetry with reconstructed continental shelf-sloperise structures. Our reconstructed bathymetry agrees with the measured ETOPO1 bathymetry at most passive margins, including the east coast of North America, north coast of the Arabian Sea, and northeast and southeast coasts of South America. There is disagreement at margins with anomalous continental shelf-slope-rise structures, such as around the Arctic Ocean, the Falkland Islands, and Indonesia.
\end{abstract}

\section{Introduction}

Reconstructing paleobathymetry represents a challenge for modeling past climates. The modern ocean bathymetry influences global climate in numerous ways. As examples, the present-day Southern Ocean bathymetry blocks flow through the Drake Passage, which has effects on the magnitude of the circumpolar current (Krupitsky et al., 1996) and the stability of the thermohaline circulation (Sijp and England, 2005). Similarly, in the Northern Hemisphere, variations in the depth of the Greenland-Iceland-Scotland Ridge have been proposed to modulate North Atlantic Deep Water formation (Wright and Miller, 1996). On the global scale, tidal dissipation is concentrated in shallow marine environments, while the generation of tides over rough ocean bathymetry has been proposed to play a major role in driving deep ocean mixing (Simmons et al., 2004).

Quantifying these processes in the geologic past requires detailed knowledge of paleobathymetry. The geometrical rules of plate tectonics and seafloor spreading provide an objective method for paleobathymetric reconstruction in the open ocean and much progress has been made in reconstructing this part of paleobathymetry younger than $\sim 200 \mathrm{Ma}$. In particular, the relationship discovered between ocean crust age and depth to basement (Parsons and Sclater, 1977) was quickly exploited to estimate paleobathymetry of the Atlantic and Indian oceans (Sclater et al., 1977a, b). Pacific Ocean paleobathymetry proved to be more challenging with its multiple spreading centers, plates of various sizes, ages and orientations, and active subduction zones (Müller et al., 1997), as well as the now lost Tethys Ocean (Heine et al., 2004). Despite these difficulties, today a convincing case has been made for the general validity of paleobathymetric reconstruc- 
tions of oceans that overly oceanic crust of known age (Xu et al., 2006; Müller et al., 2008a, b; Hayes et al., 2009).

An important element missing from these reconstructions is the shelf-slope-rise region between oceanic crust and continental shoreline. For near-present-day reconstructions, this region can be adapted from modern bathymetry. However, further back in geologic time the structure of the continentocean transition becomes increasingly less certain or unknown. Yet this region represents a critical zone for many biological, sedimentary, and oceanographic processes that influence the Earth system.

In this work we develop a method to model shelf-sloperise structure back through geologic time that is based on modern-day geometric relationships between ocean crust and shoreline, and takes into account the heterogeneity of these compound structures. Modern open ocean bathymetry, a parameterized open ocean sediment thickness and shelf-sloperise structure are joined together to form a modern ocean bathymetry. We name this reconstructed bathymetry "OESbathy" (OES: Open Earth Systems; www.openearthsystems. org).

Modern ocean bathymetry reconstructed with this methodology is used as a test case as it offers the following advantages: (1) differences can be assessed between actual ocean bathymetry and the reconstruction; (2) when applied to coupled climate models, it can be used to assess the influence of the reconstruction with respect to actual ocean bathymetry; and (3) specific components of the reconstructed bathymetry, e.g., continental shelf-slope-rise structures, can be investigated to examine their roles in the Earth system.

\section{Data}

\subsection{Ocean crust age}

For the age distribution of the oceanic crust (hereafter "ocean crust age" represented by $\tau$ ) we use the data from Müller et al. (2008a; who provide global reconstructions of ocean crust age in $1 \mathrm{Ma}$ intervals for the past $140 \mathrm{Ma}$. For each reconstructed age in Müller et al. (2008a), ocean crust age, depth to basement, and bathymetry are given. The reconstructed bathymetry based on Müller et al. (2008a) is referred to hereafter as EB08 (EB: EarthByte). The data are in $0.1^{\circ} \times 0.1^{\circ}$ resolution (3601 longitude $\times 1801$ latitude points). For this project, $000 \mathrm{Ma}$ (modern) crustal age reconstruction data are used (Fig. S1 in the Supplement).

\subsection{Modern ocean sediment thickness}

We use modern ocean sediment thickness data from Divins (2003) and Whittaker et al. (2013). These data are derived from seismic profiling of the world's ocean basins and other sources. The reported thicknesses are calculated using seismic velocity profiles that yield minimum thicknesses. Data values represent the distance between sea floor and "acoustic basement". The data are given in $5^{\prime} \times 5^{\prime}$ resolution and have been regridded to $0.1^{\circ} \times 0.1^{\circ}$ resolution values (Fig. S2) to match the EB08 grid.

\subsection{ETOPO1}

To construct the shelf-slope-rise structures, ETOPO1 modern bathymetry (Amante and Eakins, 2009) is used. We use the "Bedrock" version of ETOPO1, which is available in a $1^{\prime} \times 1^{\prime}$ resolution (earthmodels.org), regridded to $0.1^{\circ} \times 0.1^{\circ}$ resolution (Fig. S3) in order to match the EB08 grid (Fig. S1). This version of ETOPO1 includes relief of Earth's surface depicting the bedrock underneath the ice sheets. However, we use only the oceanic points in this data set, so that this has no impact on the reconstructed bathymetry.

\section{Methods}

Modern ocean basins have different types of crust, including oceanic crust, submerged continental crust, and transitions between these two types. In our reconstruction, the regions underlain by oceanic crust to which an age has been assigned are termed "open ocean" regions. The parts of the ocean basins that occupy the transitional zone between oceanic crust and the emerged continental crust are termed "shelfslope-rise" regions. These regions typically extend from the boundary of open ocean regions to the coastline. Accordingly, the OES ocean bathymetry model involves the merging of open ocean regions and shelf-slope-rise regions (Fig. 1). To accomplish the merging, map-based operations such as computing distances between locations were carried out in ArcGIS 10.1, whereas local calculations such as interpolation and statistics were carried out in Matlab R2014a. The workflow is diagrammed in Fig. S9.

\subsection{Reconstruction of open ocean regions}

Reconstruction of open ocean bathymetry starts with ocean crust age. This information is available only at locations where oceanic crust is preserved or has been reconstructed. The ocean depth to basement is the distance between mean sea level and the top of the basaltic layer of the oceanic crust. Calculation of depth to basement is based on a cooling plate model in which the vertical distance between mean sea level and basement $\omega_{\tau}$ is expressed as

$\omega_{\tau}=\omega_{0}+\omega_{\mathrm{d}}$

where the $\omega_{0}=-2639.8 \mathrm{~m}$ is the area-weighted average of mid-oceanic ridge depths from the North Pacific, eastern Atlantic and southeastern Atlantic reported in Crosby et al. (2006), and $\omega_{\mathrm{d}}$ is the change in depth due to plate cooling. Here we adopt a negative sign to denote depths below mean sea level. The change in depth due to cooling of the oceanic plate $\omega_{\mathrm{d}}$ is given by (adopted from Eq. 4.211 in Turcotte and 

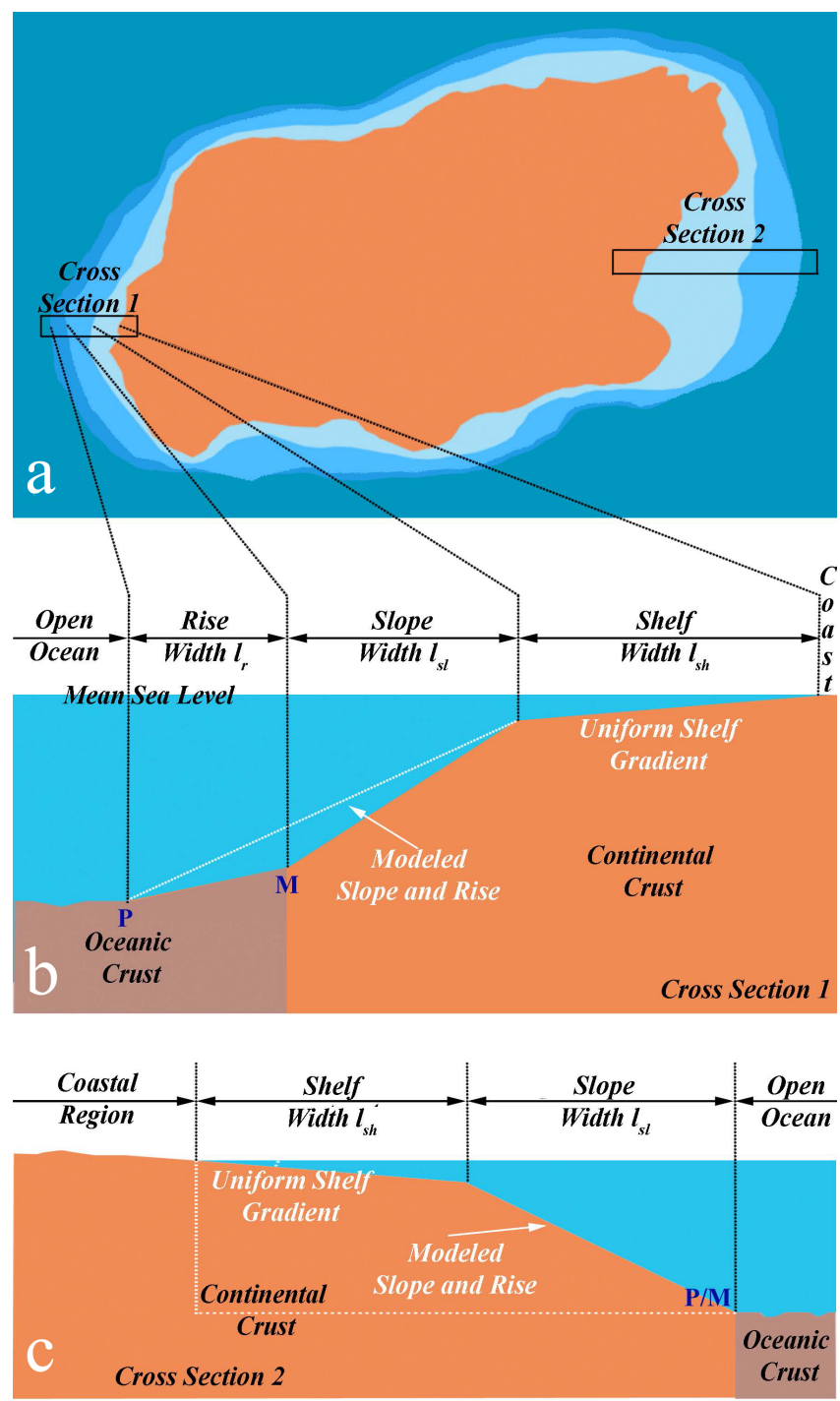

Figure 1. Bathymetric model geometry. (a) Map view showing two passive continental margins. Section 1 is a standard passive margin, Section 2 is a passive margin with an extended continental shelf. (b) Cross section of the standard passive margin with model geometry. (c) Cross section of the passive margin with extended continental shelf model geometry.

Schubert, 2014)

$$
\begin{aligned}
& \omega_{\mathrm{d}}=\frac{-\alpha \rho_{\mathrm{m}}\left(T_{\mathrm{m}}-T_{\mathrm{w}}\right) y_{L}}{\left(\rho_{\mathrm{m}}-\rho_{\mathrm{w}}\right)} \\
& {\left[\frac{1}{2}-\frac{4}{\pi^{2}} \sum_{m=0}^{\infty} \frac{1}{(1+2 \mathrm{~m})^{2}} \exp \left(\frac{-\kappa}{y_{L}^{2}}(1+2 m)^{2} \pi^{2} \tau\right)\right],}
\end{aligned}
$$

where $\alpha\left(3 \times 10^{-5} \mathrm{~K}^{-1}\right)$ is the volumetric coefficient of thermal expansion of the mantle, $\rho_{\mathrm{m}}$ is $\left(3300 \mathrm{~kg} \mathrm{~m}^{-3}\right)$ is density of the upper mantle, $\rho_{\mathrm{w}}\left(1000 \mathrm{~kg} \mathrm{~m}^{-3}\right)$ is density of sea water, $T_{\mathrm{m}}-T_{\mathrm{w}}(1300 \mathrm{~K})$ is the difference between upper mantle and ocean temperature, $\kappa\left(3.410835 \times 10^{5} \mathrm{~m}^{2} \mathrm{~s}^{-1}\right)$ is thermal
Table 1. Values for $\omega_{0}$ and $\beta$ from Crosby et al. (2006) by ocean basin, and percentage of global ocean areas used to calculate weights for the global averages.

\begin{tabular}{llrr}
\hline Regions & $\begin{array}{l}\text { \% of analyzed } \\
\text { ocean }\end{array}$ & $\begin{array}{r}\omega_{0} \\
(\mathrm{~m})\end{array}$ & $\begin{array}{r}\beta \\
\left(\mathrm{m} \mathrm{s}^{-1 / 2}\right)\end{array}$ \\
\hline North Pacific & $6.80 \%$ & -2821 & -315 \\
Eastern Atlantic & $3.38 \%$ & -2527 & -336 \\
Southeastern Atlantic & $4.35 \%$ & -2444 & -347 \\
Global average & & -2639.80 & -329.50 \\
\hline
\end{tabular}

diffusivity, and $y_{L}(2619.7 \mathrm{~m})$ is equilibrium plate thickness, all assumed to have constant values.

The equilibrium depth to basement $\omega_{\mathrm{e}}$ corresponds to the limit of $\tau \rightarrow \infty$ in Eq. (2), appropriate for the oldest crust:

$\omega_{\mathrm{e}}=\frac{-\alpha \rho_{\mathrm{m}}\left(T_{\mathrm{m}}-T_{\mathrm{w}}\right) y_{L}}{2\left(\rho_{\mathrm{m}}-\rho_{\mathrm{w}}\right)}$.

In our reconstruction we use $\omega_{\mathrm{e}}=-5875 \mathrm{~m}$, the midpoint of the range -5750 to $-6000 \mathrm{~m}$ in the oldest part of the North Pacific (Crosby et al., 2006). We assign an areaweighted average value to the parameter $\beta$ (Table 1):

$\beta=\frac{2 \alpha \rho_{\mathrm{m}}\left(T_{\mathrm{m}}-T_{\mathrm{w}}\right)}{\left(\rho_{\mathrm{m}}-\rho_{\mathrm{w}}\right)} \sqrt{\frac{\kappa}{\pi}}=329.5 \mathrm{~m} \mathrm{~s}^{-\frac{1}{2}}$,

so that

$\frac{\kappa}{y_{L}^{2}}=\left(\frac{\beta \sqrt{\pi}}{2 \omega_{\mathrm{e}}}\right)^{2}=4.97 \times 10^{-2} \mathrm{~s}^{-1}$.

In terms of $\omega_{\mathrm{e}}$ and $\beta$, Eq. (2) becomes

$$
\begin{gathered}
\omega_{\mathrm{d}}=\omega_{\mathrm{e}}\left[\frac{1}{2} \frac{4}{\pi^{2}} \sum_{m=0}^{\infty} \frac{1}{(1+2 \mathrm{~m})^{2}}\right. \\
\left.\exp \left(\frac{-\beta \sqrt{\pi}}{2 \omega_{\mathrm{e}}^{2}}(1+2 \mathrm{~m})^{2} \pi^{2} \tau\right)\right] .
\end{gathered}
$$

We include the first 25 terms in the sum of Eq. (6) to ensure convergence. Lastly, the depth to basement is calculated with Eq. (1).

\subsection{Reconstruction of ocean sediment thickness and isostatic correction}

The addition of sediment and an isostatic correction from sediment loading of the oceanic crust (e.g., Célérier, 1988) is needed to complete the bathymetry. A parameterized multilayer sediment cover, called "OES sediment thickness" (Figs. 2, 3), was isostatically added on top of the depth to basement $\omega_{\tau}$ (Fig. 4) to complete the open ocean bathymetry (Fig. 5). OES sediment thickness (Fig. 3) was parameterized based on a third-degree polynomial fit between areacorrected global sediment thickness data (Divins, 2003; 


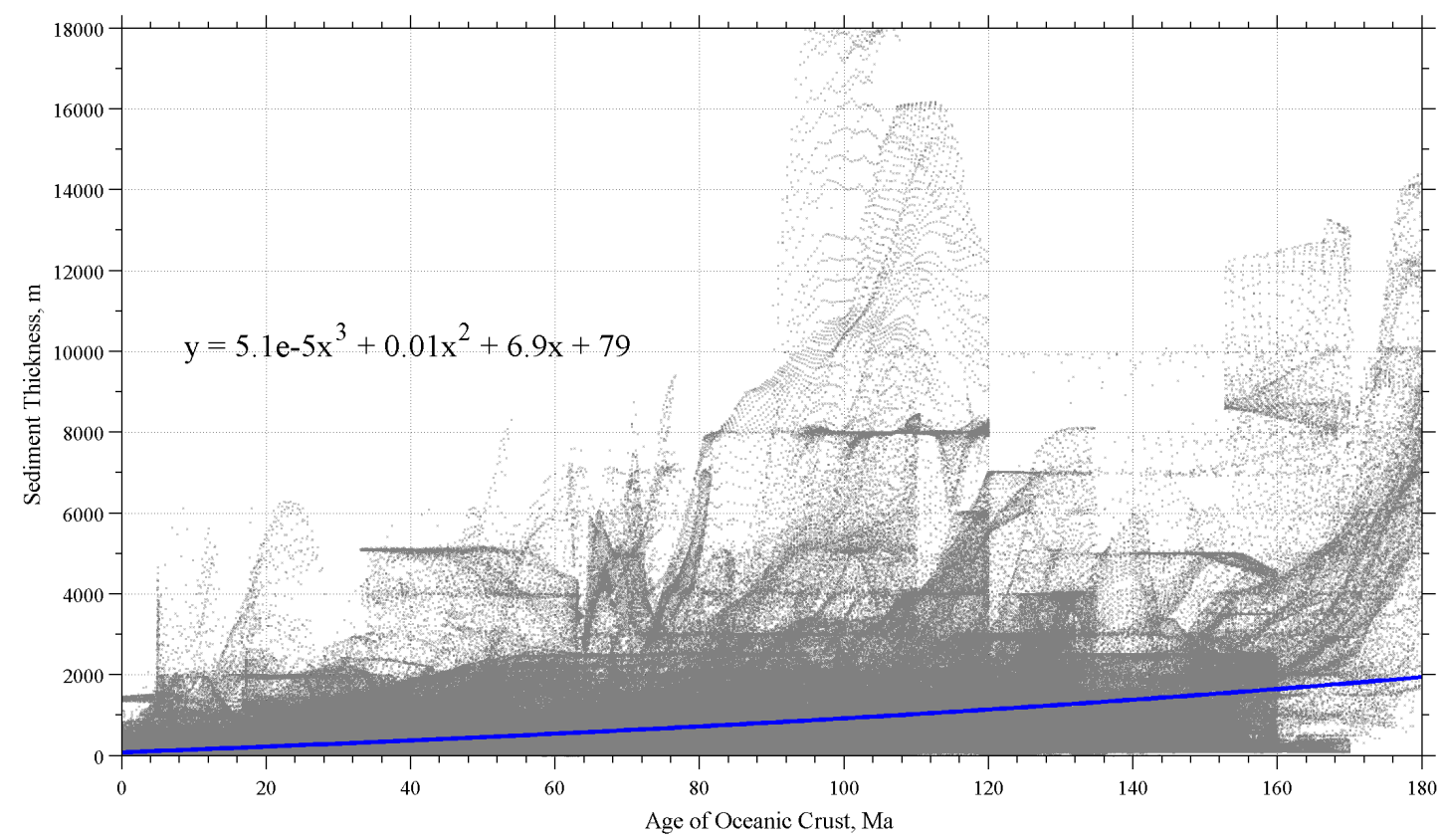

Figure 2. Polynomial fit of sediment thickness as a function of ocean crust age using area-corrected global sediment data from Divins (2003) and Whittaker et al. (2013) (Fig. S2) and age of the underlying oceanic crust from Müller et al. (2008a) (Fig. S1).

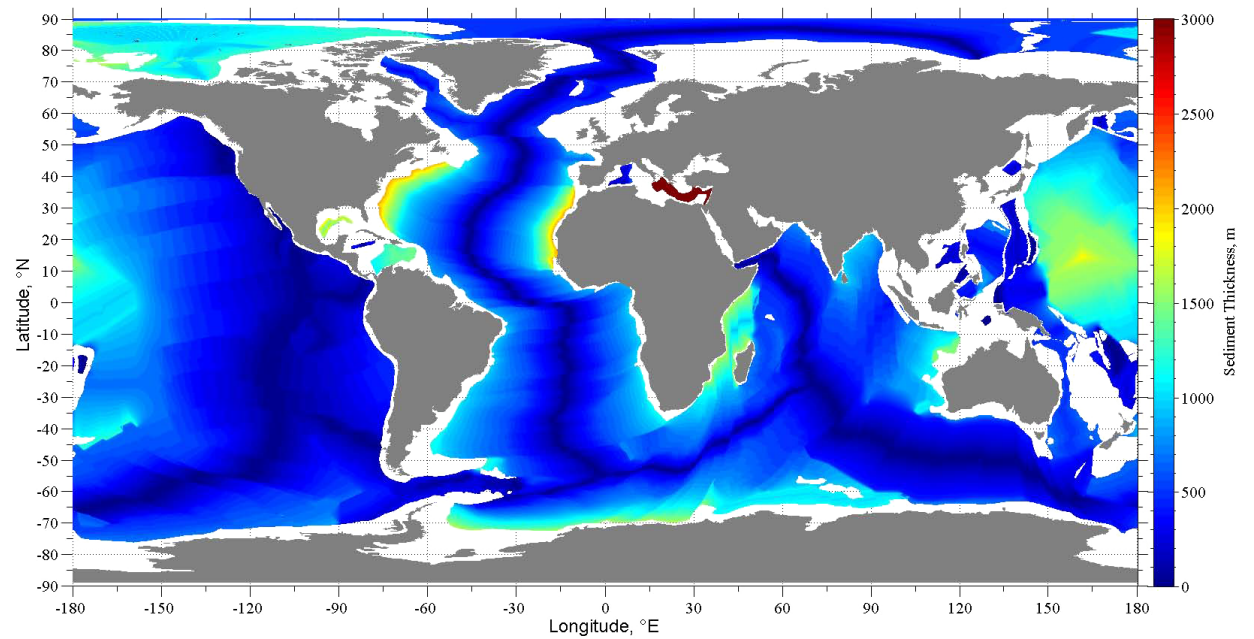

Figure 3. OES model sediment thickness based on the sediment thickness parameterization in Fig. 2.

Whittaker et al., 2013) and age of the underlying oceanic crust $\tau$. Sediment loading was calculated using a multicomponent sediment layer with varying sediment densities given in Table 2 in $100 \mathrm{~m}$ increments of the sediment. The variable sediment densities were calculated from a linear extrapolation of sediment densities in Crosby et al. (2006) (Table S1 in the Supplement). For the isostatic correction, in each $100 \mathrm{~m}$ sediment layer we calculate an adjusted thickness given by

$D_{z}=\frac{100\left(\rho_{\mathrm{m}}-\rho_{z}\right)}{\left(\rho_{\mathrm{m}}-\rho_{\mathrm{W}}\right)}$, where $\rho_{z}$ is the density of the $z$ th layer, $\rho_{\mathrm{m}}=3300 \mathrm{~kg} \mathrm{~m}^{-3}$ and $\rho_{\mathrm{w}}=1000 \mathrm{~kg} \mathrm{~m}^{-3}$. The sediment model has a total of 16 layers in which the basal layer includes all sediment deeper than $1500 \mathrm{~m}$. For a given location we sum $D_{z}$ to obtain the isostatically adjusted total sediment thickness, which is then added to the depth to basement to obtain the open ocean bathymetry. This loading correction is similar to procedures used by Crough (1983) and Sykes (1996). 


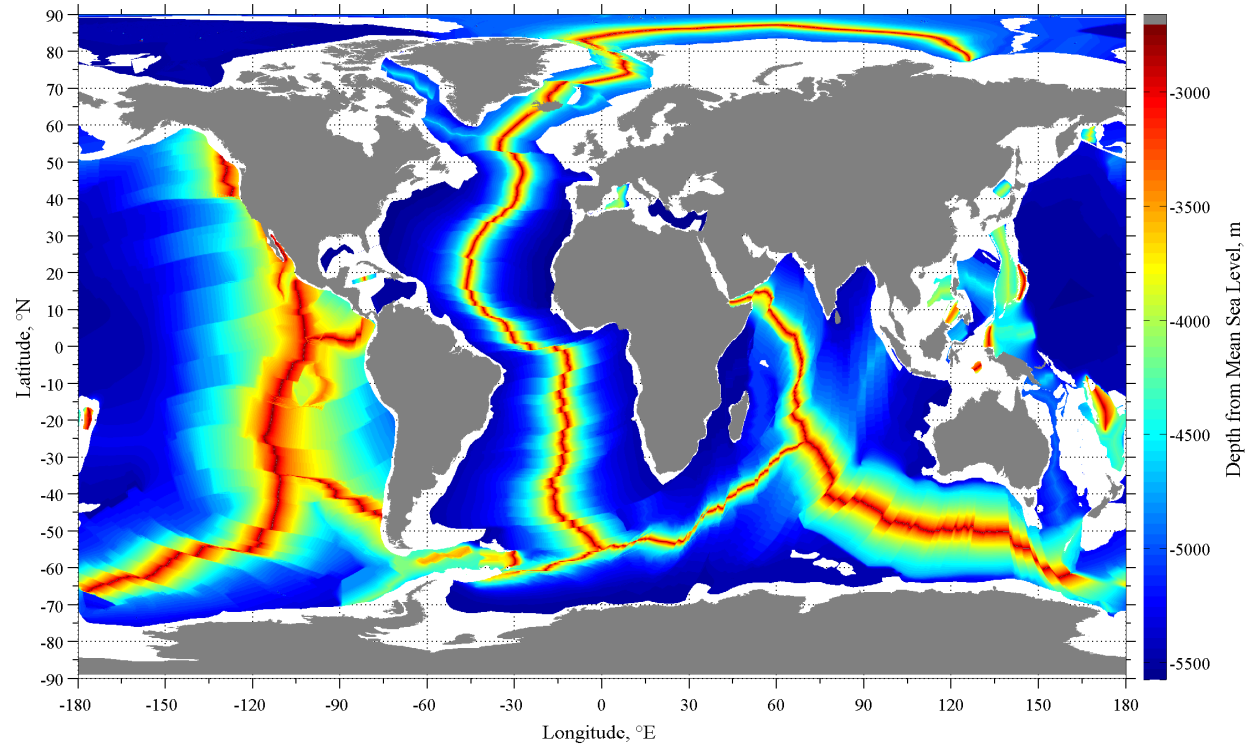

Figure 4. OES model depth to basement calculated using Eqs. (1) and (6) and Table 1 in open ocean regions underlain by ocean crust of known age.

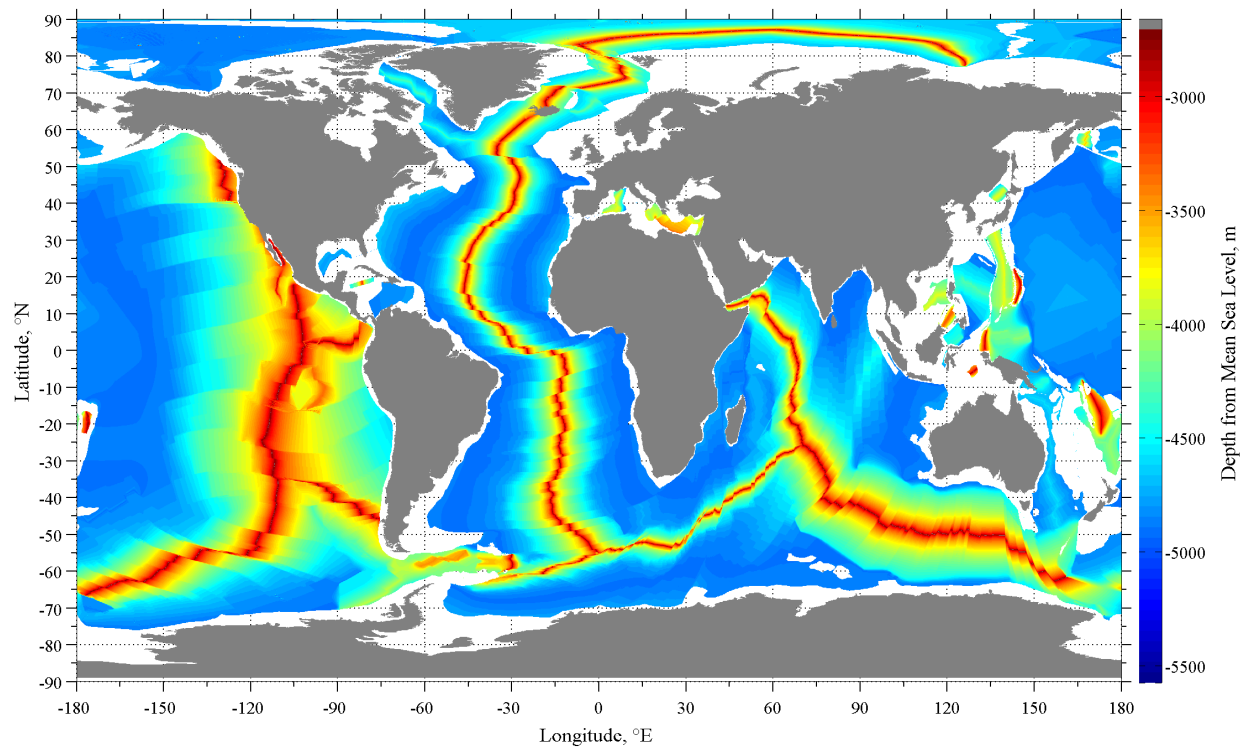

Figure 5. OES model bathymetry for the open ocean regions with isostatically adjusted multilayer sediment of varying densities shown in Table 2. The sediment thickness was parameterized as in Fig. 2. The varying sediment densities are from Table 2.

\subsection{Reconstruction of shelf-slope-rise structures}

To model the shelf-slope-rise structure, profiles from various modern shelf-slope-rise structures at active and passive margin regions from ETOPO1 were examined, along with their corresponding sediment thicknesses taken from Divins (2003). As a representative active margin, the west coast of South America was chosen (Fig. 6). For passive margins, the Atlantic Ocean (north, south and central) and part of the Southern Ocean were chosen as representative because their complete rifting history is preserved (Figs. 7, S4).

Profiles from these representative regions were used to parameterize the widths of the continental shelf, slope and rise as follows. The basic parameters of the shelf-slope-rise structure (Fig. 8a) include continental shelf width $l_{\mathrm{sh}}$, continental slope width $l_{\mathrm{sl}}$ and continental rise width $l_{\mathrm{r}}$. The location of the maximum extent of oceanic crust according to EB08 is labeled $\mathrm{M}$, and another anchor point labeled $\mathrm{P}$ marks the boundary between the shelf-slope-rise structure and the open 

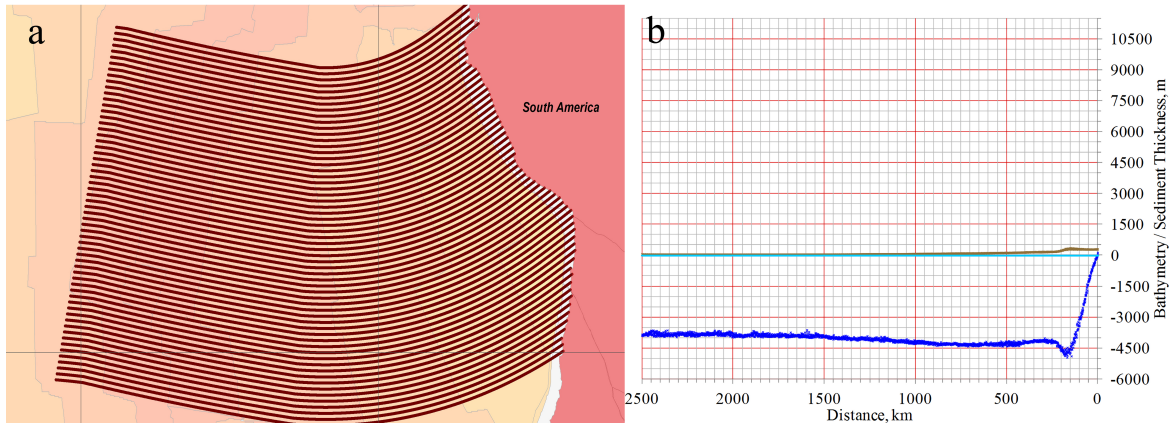

Figure 6. Representative active margin profile off the west coast of South America. (a) Transects (brown lines) drawn by smoothly connecting transform fault segments using maps by Scotese (2011). Ocean color represents ocean crust age from the PALEOMAP Project (Scotese, 2011). Continents are from the ESRI standard shapefile data library in ArcGIS 10.1. (b) Average profile based on all transects in (a). Light blue line represents mean sea level (m.s.l.), brown points represent sediment thickness obtained from Divins (2003) and dark blue points represent bathymetry from ETOPO1.
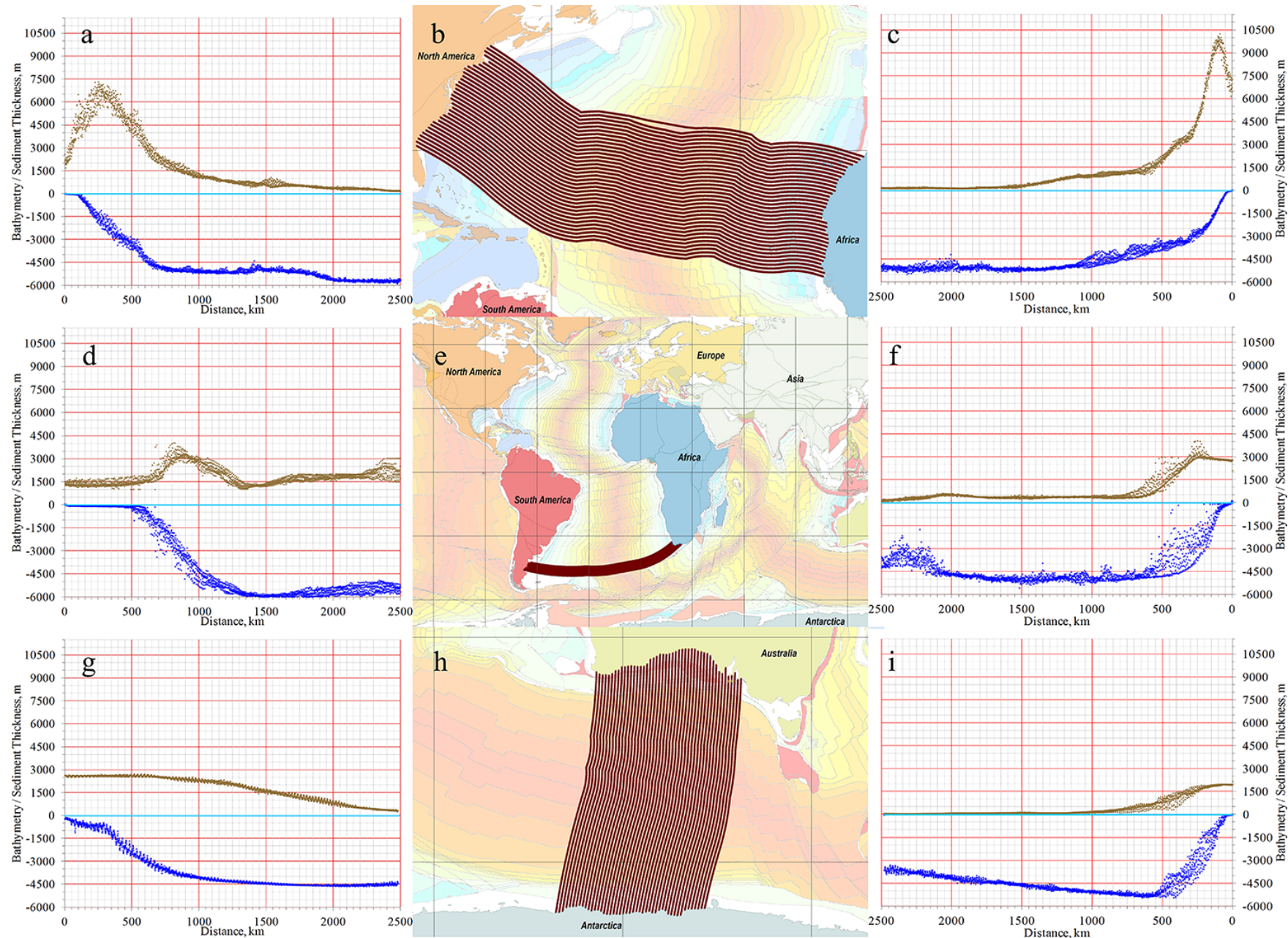

Figure 7. Representative passive margin profiles (shelf-slope-rise structure) from the Atlantic and Southern oceans. Ocean colors represent ocean crust age from the PALEOMAP Project (Scotese, 2011). Continents are from the ESRI standard shapefile data library in ArcGIS 10.1. (b), (e) and (h). Transects (brown lines) drawn by smoothly connecting transform fault segments using maps by Scotese (2011). (a), (c), (d), (f), (g) and (i): average profiles based on west and east parts of all transects in (b), (e) and (h). Light blue line represents mean sea level, brown points represent sediment thickness obtained from Divins (2003) and dark blue points represent bathymetry from ETOPO1. Figure S4 displays all 17 transects used, where the ones displayed here appear as Set 4 (a-c), Set 15 (d-f) and Set 17 (g-i). 
Table 2. Profile of sediment density vs. depth below sea floor used in our reconstruction. These sediment densities were calculated from a linear extrapolation of the data in Table S1.

\begin{tabular}{rr}
\hline $\begin{array}{r}\text { Depth } \\
(\mathrm{m})\end{array}$ & $\begin{array}{r}\text { Density of } \\
\text { sediment }\left(\mathrm{kg} \mathrm{m}^{-3}\right)\end{array}$ \\
\hline $0-100$ & 1670 \\
$100-200$ & 1740 \\
$200-300$ & 1810 \\
$300-400$ & 1880 \\
$400-500$ & 1950 \\
$500-600$ & 2020 \\
$600-700$ & 2090 \\
$700-800$ & 2160 \\
$800-900$ & 2230 \\
$900-1000$ & 2300 \\
$1000-1100$ & 2370 \\
$1100-1200$ & 2440 \\
$1200-1300$ & 2510 \\
$1300-1400$ & 2580 \\
$1400-1500$ & 2650 \\
$>1500$ & 2720 \\
\hline
\end{tabular}

ocean. These are derived as

$l_{\mathrm{sh}}+l_{\mathrm{sl}}=M$,

$l_{\mathrm{sh}}+l_{\mathrm{sl}}+l_{\mathrm{r}}=P$,

$l_{\mathrm{r}}=-0.290 l_{\mathrm{sl}}+437.2$,

$l_{\mathrm{s} 1}+l_{\mathrm{r}}=-8.28 \times 10^{-3} l_{\mathrm{sh}}^{2}+5.486 l_{\mathrm{sh}}$,

where $M$ and $P$ are the distances of the coastline from points $\mathrm{M}$ and $\mathrm{P}$, respectively.

The numerical coefficients in Eq. (8a) and (8d) were obtained from fits to ETOPO1 profiles (Figs. 6, 7, S4). In Fig. $8 \mathrm{~b}$ we plot the width of the slope + rise versus the width of the shelf from a set of passive margin regions that span a range of shelf widths. We then fit a parabola to this data, constraining the parabola to pass through the origin in order to model the structure at active continental margins. We apply this parabolic fit to active margins and to passive margins where the shelf width is less than the parabola maximum, approximately $350 \mathrm{~km}$. Shelves having widths greater than this maximum are treated individually as special cases.

To determine the corresponding depths, we work outward from the coast. First we apply a uniform gradient of $3.2^{\circ}$ in depth over the width of the shelf. This value of the shelf gradient was obtained from analysis of 17 ETOPO1 transects (Fig. S4). For the depth distribution along the slope and rise, we assume another uniform gradient, as illustrated in Fig. 8a, joining the depth at the shelf break with the depth calculated for the open ocean at point $P$.

This methodology works for all shelf-slope-rise regions except where the shelf is anomalously extended, for example, north of Siberia, the Falkland Islands region, and the complex
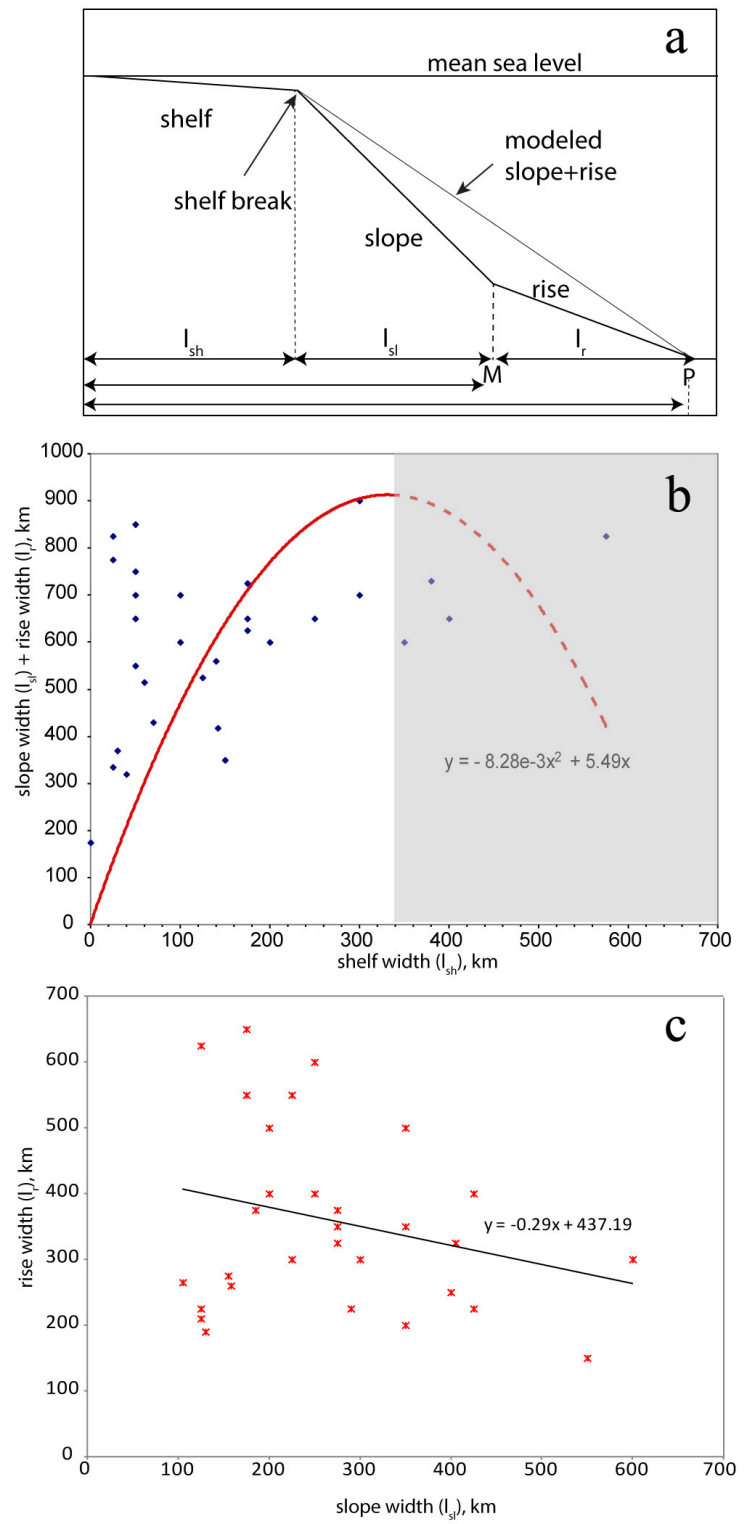

Figure 8. Modeling shelf-slope-rise structure as in Fig. 1. (a) The shelf-slope-rise parameterization shown in a cross section through a passive continental margin. Parameters are $l_{\mathrm{sh}}$, continental shelf width; $l_{\mathrm{sl}}$, continental slope width; $l_{\mathrm{r}}$, rise width; $M$, maximum extent of oceanic crust (closest to the coastline) from EB08; and $P$, the boundary between the shelf-slope-rise structure and the open ocean. (b) Relationship between shelf width $\left(l_{\mathrm{sh}}\right)$ and slope width + rise width $\left(l_{\mathrm{s} l}+l_{\mathrm{r}}\right)$ in the modern oceans from ETOPO1. Diamonds represent measurements from the east/west coasts of the Atlantic Ocean, and north/south coasts of the Southern Ocean between Australia and Antarctica as shown in Fig. 5. The red line is a parabolic fit; only the solid portion of the fit was used; shading indicates region requiring reconstruction by hand. (c) Relationship between slope width $\left(l_{\mathrm{sl}}\right)$ and rise width $\left(l_{\mathrm{r}}\right)$ in the modern oceans from ETOPO1. Red crosses represent measurements at the same locations used in Fig. 8b. The black line is a linear fit. 
regions in Southeast Asia. If the $\mathrm{M}$ point is too far from the coastline, so that $l_{\mathrm{sh}}+l_{\mathrm{sl}}>800 \mathrm{~km}$, or too close to the coastline, so that $l_{\mathrm{sh}}+l_{\mathrm{sl}}<100 \mathrm{~km}$, then the relationship among the three widths no longer holds. For these regions we assume that $P=M$ (Fig. 1c). To complete the reconstruction, these regions were filled by interpolation from neighboring regions.

\section{Results}

\subsection{Reconstructed shelf-slope-rise structures}

ETOPO1 bathymetry reveals that active margins lack extensive shelves (Fig. 6) and their slope gradient is anomalously large. Likewise, sediment thickness profiles show that active margins have little sediment cover near or far from the coast. In particular, sediment thickness on the shelves of active margins rarely exceeds $250 \mathrm{~m}$ and gradually thins out beyond the subduction zone towards the open ocean.

In contrast to active margins, passive margins are characterized by significant shelf-slope-rise regions. Three out of the 16 passive margin cross sections studied are shown in Fig. 7. The extent of the shelf region varies substantially along passive margin coastlines, which accounts for the scatter among the profiles in Fig. 7. For example, in the profile between the southern tips of Africa and South America, the South American side has a very wide, platform-like shelf region that extends for more than $500 \mathrm{~km}$, whereas on the African side the shelf is at most $100 \mathrm{~km}$ wide.

The bathymetric gradients at passive continental margin slopes in Fig. S5 vary significantly, from -0.004 to -0.018 . Compared to active margins, passive margins are characterized by greater thickness of sediments and more lateral variability. The greater sediment thickness on passive margins and its greater lateral variability are evident in the 13 passive margin transects shown in Fig. S4.

Figure 8 shows the relationship between the widths of the shelves and the widths of the adjacent slope-rise structure. A transect east-northeast of Newfoundland in the northern part of the Atlantic Ocean (Fig. S4, Set 3, center panel) includes $300 \mathrm{~km}$ of continental shelf and nearly $900 \mathrm{~km}$ of continental slope-plus-rise structure. The presence of the widely extended Gulf of St. Lawrence may contribute to this anomaly.

\subsection{Reconstructed open ocean regions}

Our depth-to-basement reconstruction is shown in Fig. 4. The isostatically adjusted, sediment-loaded model bathymetry of the open ocean is shown in Fig. 5, for which only ocean basin areas with ocean crust ages have an assigned bathymetry. The gap between the coastline and open ocean bathymetry is reconstructed with the shelf-slope-rise model described in Sect. 3.3.

The mid-oceanic ridge systems in our open ocean bathymetry in Fig. 4 have an average depth of approximately
$-2675 \mathrm{~m}$. Away from the mid-ocean ridges, ocean depth increases systematically, and reaches a maximum depth of approximately $-5575 \mathrm{~m}$ at old crustal ages. In Fig. 5, the open ocean bathymetry is shown with the modeled sediment cover from Fig. 3 isostatically loaded on to it. With this sediment cover added, the bathymetry ranges between -2675 and $-4900 \mathrm{~m}$ in the open ocean regions and the maximum depth of the reconstructed bathymetry is approximately $-6500 \mathrm{~m}$. The depth range between -4900 and $-6500 \mathrm{~m}$ is associated with old ocean crust (crustal age in the range of $\tau=100$ $120 \mathrm{Ma}$ ) along the flanks of the Atlantic, Pacific, Southern and Indian oceans, and the Bay of Bengal.

\subsection{Model evaluation}

The addition of the shelf-slope-rise model completes the OESbathy (Fig. 9), though excluded are ocean islands, seamounts, trenches, plateaus and other localized anomalies plus the underlying dynamical topography. Below we evaluate the modeled OESbathy with respect to ETOPO1 and EB08.

\subsubsection{Statistics}

Basic statistics of OESbathy, ETOPO1 and EB08 are summarized in Table 3, which highlights major differences among the bathymetries. Compared to the $-10714 \mathrm{~m}$ maximum depth of ETOPO1, OESbathy maximum depth is $-6522 \mathrm{~m}$, while the deepest point of EB08 is only $-5267 \mathrm{~m}$. These differences from ETOPO1 are due to the absence of trenches in the reconstructions. The average ocean depths for the ETOPO1, OESbathy and EB08 are $-3346,-3592$ and $-4474 \mathrm{~m}$, respectively, signifying that EB08 in particular is very deep compared to ETOPO1. The standard deviations of the ETOPO1, OESbathy and EB08 are 1772.25, 1668.52 and $785.08 \mathrm{~m}$, respectively. These values suggest that compared to ETOPO1, the EB08 is overall very smooth, whereas OES bathymetry has a variability that is comparable to ETOPO1.

We also assessed the skewness and kurtosis of the three bathymetries. Skewness is a measure of the asymmetry of data around their mean, and is zero for a symmetric distribution. The skewness of OESbathy (1.34) lies between ETOPO1 (0.67) and EB08 (1.81), indicating a closer fit of OESbathy to ETOPO1 than EB08 to ETOPO1. Kurtosis is a measure of how outlier-prone a distribution is. Kurtosis equals to 3 for a normal distribution, whereas outlier-prone distributions have a kurtosis greater than 3 , and less outlierprone distributions have a kurtosis less than 3. For the three bathymetries the kurtosis values are 2.30 (OESbathy), 3.26 (ETOPO1) and 7.69 (EB08). It should be noted that OESbathy does not take into account large igneous provinces (LIPs), seamounts or plateaus, whereas EB08 has incorporated some of the major LIPs. 


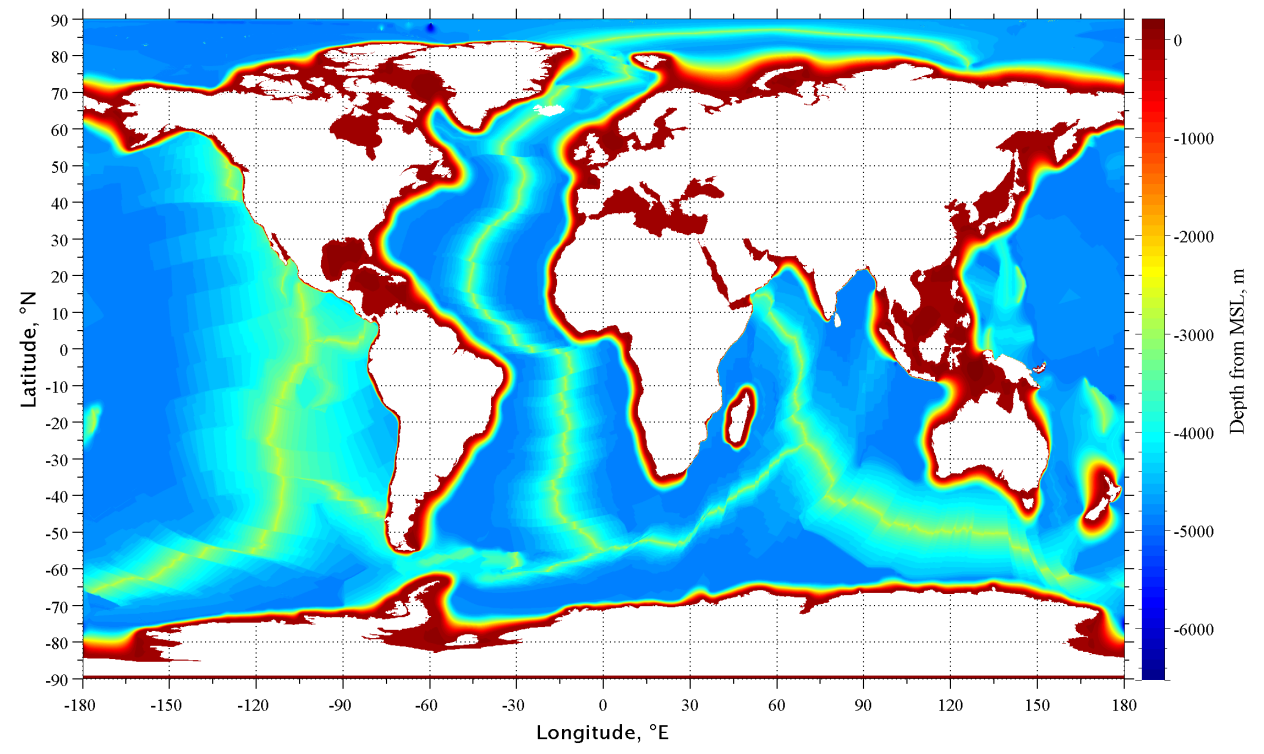

Figure 9. The full OESbathy model including open ocean regions and shelf-slope-rise structures.

Table 3. Statistics of three global ocean bathymetries: ETOPO1 is from Amante and Eakins (2009), EB08 is from Müller et al. (2008a), and OESbathy is the result of this study. Mean, median, mode, minimum, maximum and standard deviations (SDs) are in meters; skewness (measure of horizontal symmetry of data distribution) and kurtosis (tall and sharpness of the central peak of data distribution) are dimensionless.

\begin{tabular}{lrrrrrrrr}
\hline Bathymetry & Max & Min & Average & Median & Mode & SD & Skewness & Kurtosis \\
\hline OESbathy & -6522.17 & 204.5 & -3591.83 & -4321.07 & -6.22 & 1668.52 & 1.34 & 3.26 \\
ETOPO1 (ocean only) & -10714 & 3933 & -3346.41 & -3841 & -1 & 1772.25 & 0.67 & 2.30 \\
EB08 & -5266.97 & 422.75 & -4473.83 & -4678.47 & -4231.85 & 785.08 & 1.81 & 7.69 \\
ETOPO1-OESbathy & 8812.7 & -9231.41 & 242.53 & 1.43 & 5.22 & 1270.46 & 0.53 & 5.71 \\
ETOPO1-EB08 & 9129.19 & -6349.64 & 380.93 & 151.92 & 108.01 & 1009.99 & 1.22 & 6.40 \\
OESbathy-EB08 & 5264.95 & -4769.50 & 216.31 & 169.99 & 94.59 & 921.59 & 1.31 & 17.12 \\
\hline
\end{tabular}

\subsubsection{Difference maps}

To assess the quality of our results, we difference OESbathy from ETOPO1 in Fig. 10, with positive values corresponding to regions where OESbathy is deeper than ETOPO1 and negative values corresponding to regions where OESbathy is shallower than ETOPO1. As described in Sect. 3.3, interpolations were used in certain regions to complete the reconstruction, for example, the Falkland Island region, north of Siberia, and the complex regions around SE Asia. These regions show significant deviations from ETOPO1; in general, OESbathy is much deeper. Some shelf-slope-rise structures are shallower in OESbathy than ETOPO1, such as around the margins of the central Atlantic, whereas in other areas OESbathy is deeper, such as along the east coast of Africa, the Bay of Bengal and the Arctic Ocean margin. Owing to the absence of seamounts and plateaus in OESbathy, those areas display large positive anomalies.

A difference map between the OES sediment thickness (Fig. 3) and the Divins (2003) global ocean sediment
(Fig. S2) has been calculated for the open ocean regions. Figure $\mathrm{S} 6$ shows that the most noticeable differences occur close to the continent margins (edge of the ocean crust), where large negative values indicate that the modeled sediment thicknesses are much less than actual sediment thicknesses. Otherwise, over a substantial part the open ocean, especially on ridge flanks, the differences in Fig. S6 are close to zero, indicating a good fit between OES sediment thickness and $\mathrm{Di}-$ vins' sediment thickness. In the Atlantic abyssal plains, however, OES sediment thickness generally exceeds the Divins sediment thickness. Likewise, OES sediment thickness exceeds Divins' sediment thickness (up to $0.5 \mathrm{~km}$ ) in the eastern Indian Ocean (off the coast of Australia) and significantly exceeds (by more than $1 \mathrm{~km}$ ) measured sediment thickness throughout the western Pacific Ocean. Figure S6 can also be compared with Fig. S5 in Müller et al. (2008b), which is an equivalent difference map between their more detailed sediment model and Divins' sediment thickness. 


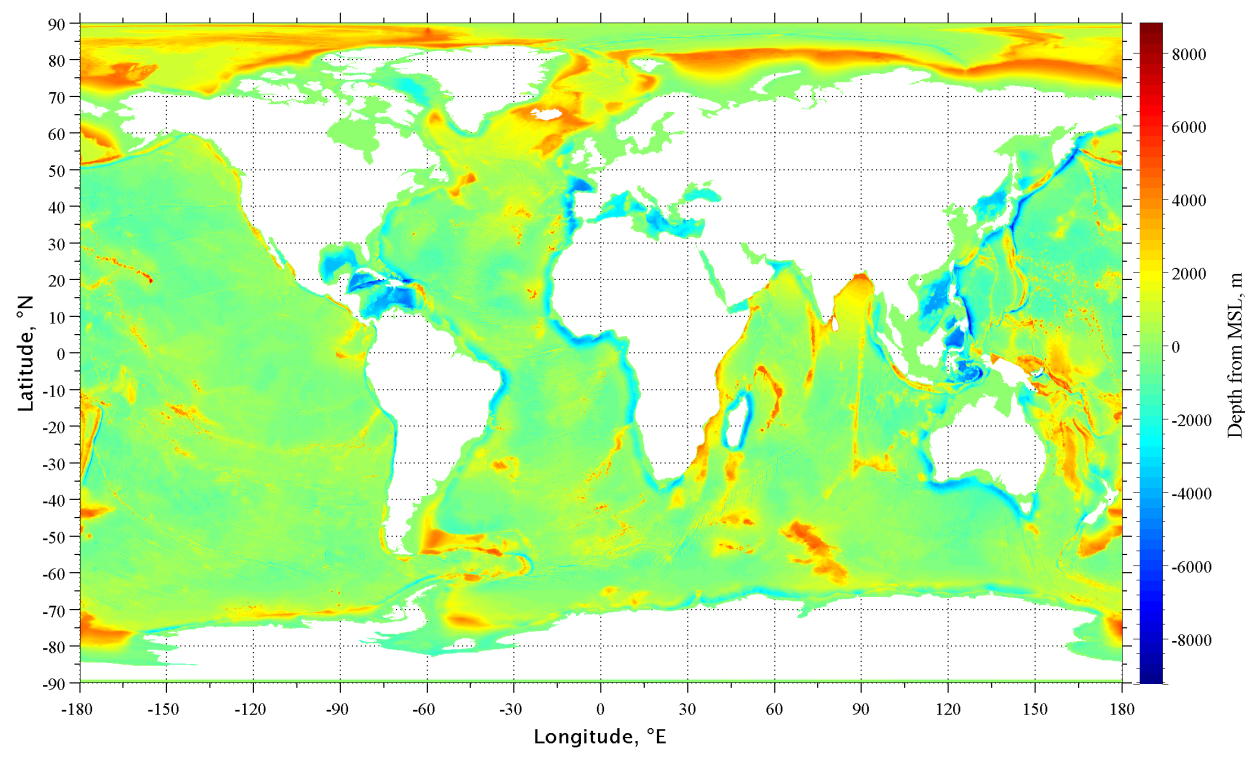

Figure 10. ETOPO1 minus OESbathy. In regions with positive values OESbathy is deeper than ETOPO1, and in regions with negative values OESbathy is shallower than ETOPO1.

\subsubsection{Shelf-slope-rise profiles}

Randomly selected shelf-slope-rise cross sections from all continents, here referred to as "profiles", are compared for OESbathy, EB08 and ETOPO1 (Figs. 11 and S7). The profiles shown in Fig. 11b, c, g and j agree well with ETOPO1, while those in Fig. 11d and e are partial fits, and the profiles in Fig. 11f, h and i are poor fits. In all profiles, EB08 is shown only for the deep oceans with no continental shelf or slope and as a result none of the EB08 profiles reach the coast. Of the 64 profiles depicted, nearly $50 \%$ fit well with ETOPO1.

Along Profile 1 from the North Pacific (Fig. 11b), OESbathy is in good agreement with the ETOPO1, especially for the shelf and slope. Beyond $550 \mathrm{~km}$, OESbathy is deeper and lacks the local variations of ETOPO1, such as from the seamounts. EB08 is even deeper than OESbathy along this profile with a similar lack of local variation. Along the northeast coast of South America and Australia (Fig. 11c, g), Profiles 12 and 39, OESbathy agrees with ETOPO1, whereas the EB08 is deeper than both OESbathy and ETOPO1. Figure $11 \mathrm{j}$ shows Profile 61 off the coast of Delaware, USA. Here, there is good agreement between ETOPO1 and OESbathy from the shelf-slope-rise region to the open ocean region out to $\sim 600 \mathrm{~km}$ from the coast.

Profiles 20 and 22 (Fig. 11d, e) are taken from coast of Nigeria and the southern tip of Africa. Here, OESbathy has a partial fit with ETOPO1. The OESbathy shelf in both profiles is wider than ETOPO1 and, as a result, the OESbathy slope+rise is too steep. However, the fit improves in the open ocean along both profiles.
Profiles 58 and 60 (Fig. 11h, i) are from the northern part of Eurasia. This region was filled in by interpolation from nearby regions, because our parameterization fails to model this extremely wide shelf. Hence, along these two profiles there is poor agreement between ETOPO1 and OESbathy. The ETOPO1 shelf is very shallow $(<1000 \mathrm{~m}$ below sea level), whereas the OESbathy shelf is deeper with a steeper gradient on the slope-rise structure. Similar deviations occur in Profile 33 (Fig. 11f) from the Bay of Bengal, where an enormous pile of sediment from the Ganges system has accumulated, resulting in a much shallower ETOPO1 compared to OESbathy.

\section{Discussion}

\subsection{Shelf-slope-rise internal architecture}

Examples of the global ocean sediment thickness data of Divins (2003) are displayed as cross-sectional profiles from the coastline to the abyssal ocean in Figs. 6, 7 and S4. In these profiles, the sediment thickness contribution is shown separately from ETOPO1. These profiles highlight the fact that the greatest sediment accumulations occur in the shelf-sloperise regions, whereas open ocean regions accumulate far less. Active margins as in Fig. 6 have thin sediment cover, whereas passive margins as in Figs. 7 and S4 have much thicker sediment cover. On the passive margins, lateral heterogeneity in sediment thickness reflects a complex buried topography of the seafloor on which the sediment accumulated. This topography consists of rifted, stretched and sagged lithosphere in kilometer-scale relief, first in-filled by syn-rift sediment and then buried by post-rift sediment (e.g., Watts et al., 2009; 

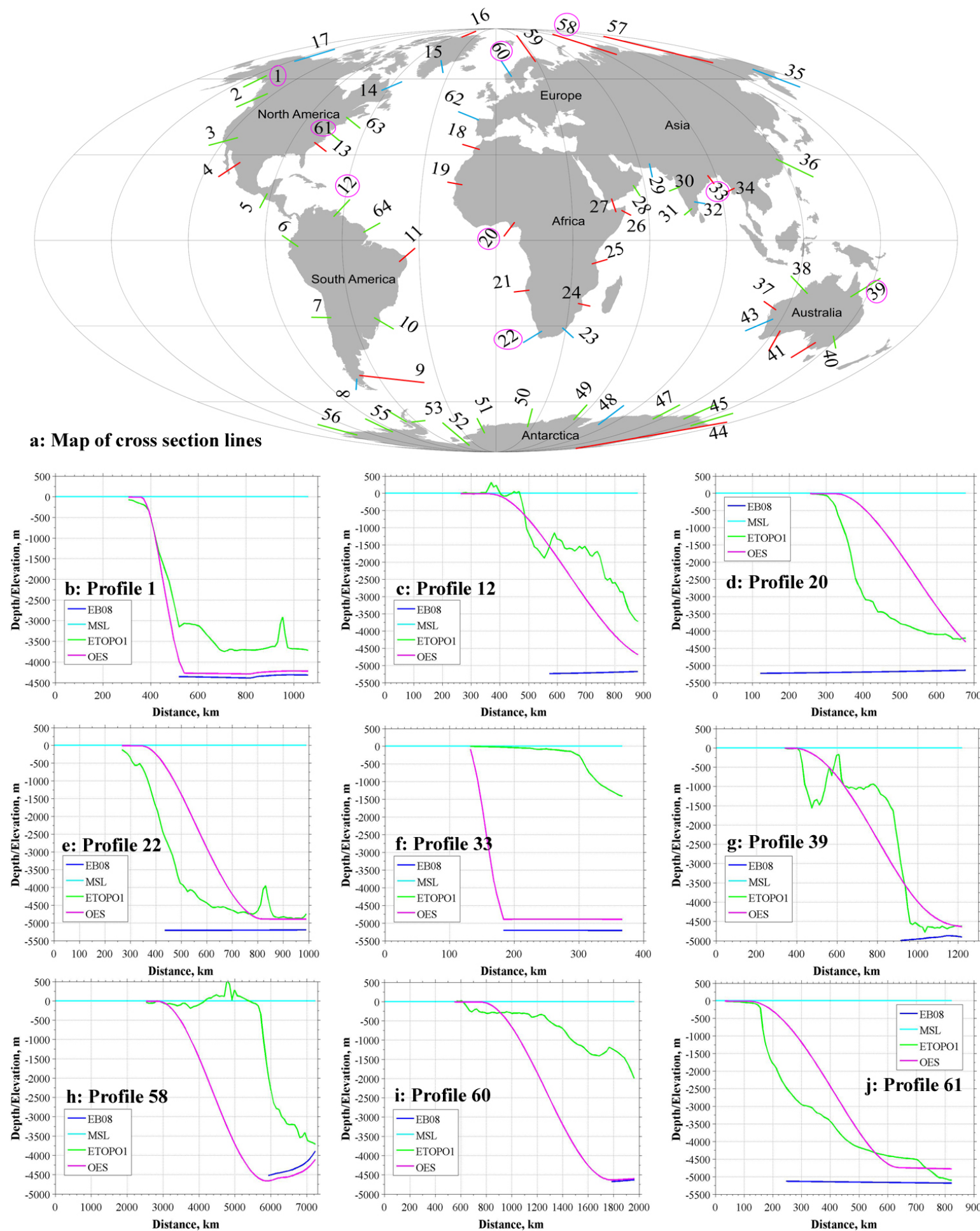

Figure 11. (a) Location of 61 profiles comparing OESbathy (Fig. 9) with ETOPO1 and EB08. (b-j) Representative profiles at locations shown in Figs. 6 and 7. 

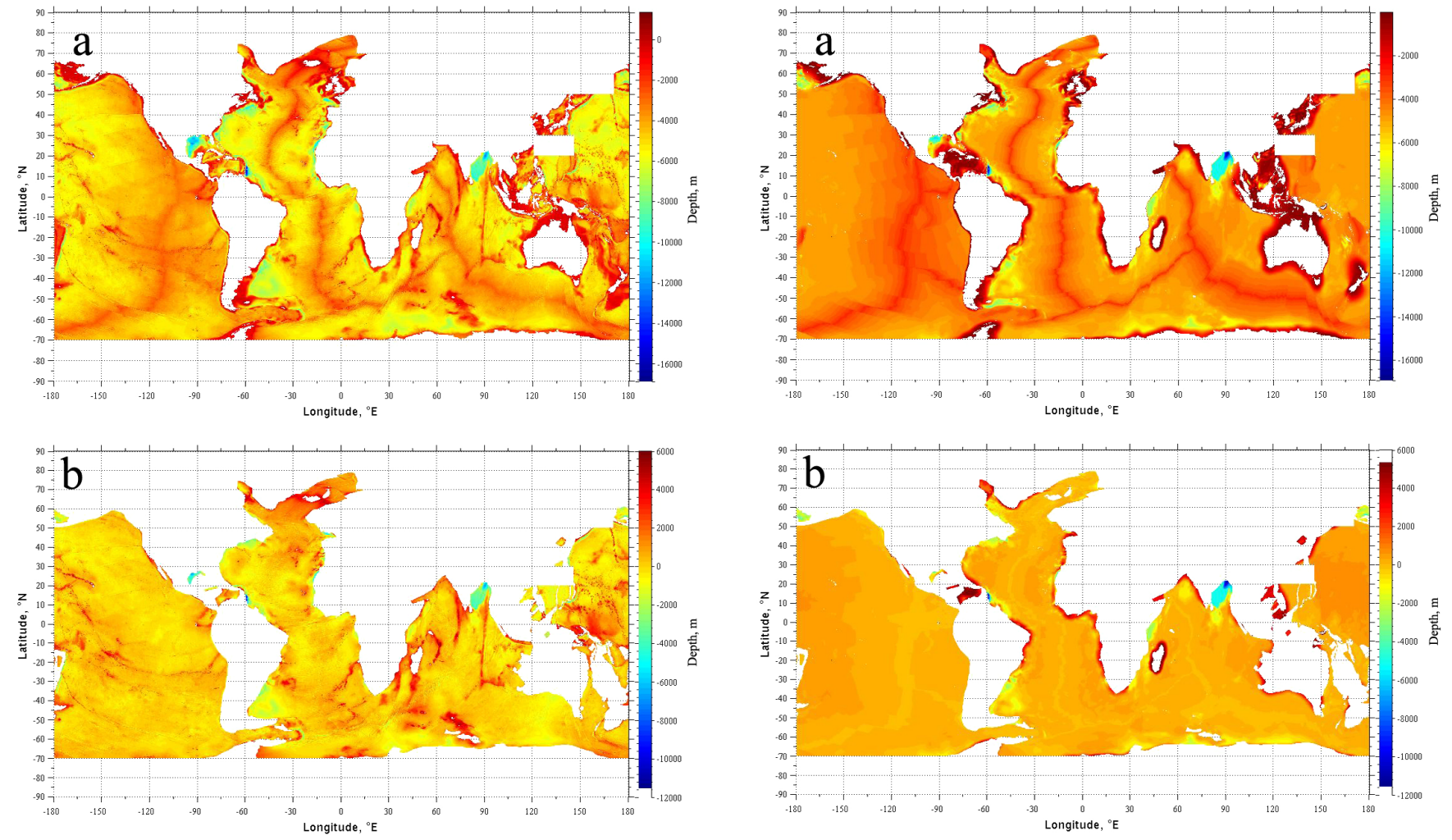

Figure 12. Residual ocean bathymetries. (a) ETOPO1 bathymetry minus the global oceanic sediment thickness from Divins (2003) with isostatic readjustment applied. (b) The bathymetry from (a) minus the depth-to-basement bathymetry shown in Fig. 4.

Davison and Underhill, 2012). The thickness profiles of the Atlantic margins reflect subsurface graben structures related to the Jurassic-Cretaceous rifting of Pangea (Peron-Pinvidic et al., 2013; Franke, 2013).

The shelf-slope-rise model in Figs. 1 and 8 is based on modern-day bathymetry with three well-defined gradient changes from the coast to the open (deep) ocean. There is no accounting in the model for the complex types of internal architecture in shelf-slope-rise structures just described.

For paleo-ocean reconstructions, extrapolation back through time will produce proportionate narrowing of shelfslope-rise geometry at passive margins. Highly variable internal structures strongly suggest that simple backward extrapolation may not accurately produce paleo-shelf-sloperise bathymetries, especially for the oldest paleo-oceans. Rifting depends on local lithospheric strength, mantle dynamics, and global tectonics, all contributing to the evolution of a passive margin in ways that are not easy to parameterize (Ziegler and Cloetingh, 2003; Corti et al., 2004). Thus, additional data such as from seismic profiling and ocean margin drill cores must be consulted before applying these types of corrections for deep time reconstructions.

Lastly, we point out that our shelf-slope-rise formulation constitutes a marked improvement over simple bathymetric

Figure 13. (a) OES model bathymetry minus the global oceanic sediment thickness from Divins (2003) with isostatic correction applied. (b) The bathymetry from (a) minus the depth-to-basement bathymetry shown in Fig. 4.

interpolation between the coastline and oldest oceanic crust. Bathymetric interpolation would not resolve the extreme differences in slope between shelf and rise, nor would it faithfully represent the heterogeneity in shelf lengths found in the modern ocean.

\subsection{Residual bathymetry}

The Divins sediment thickness (Fig. S2) may be isostatically subtracted from ETOPO1 (Fig. S3) to yield a sedimentstripped bathymetry that should be in isostatic equilibrium with the mantle (Fig. 12a). To detect deviations in this bathymetry from isostatic equilibrium, the OESbathymodeled depth to basement (Fig. 4), which is in isostatic equilibrium with the mantle (Eqs. 2, 3), is subtracted from the sediment-stripped bathymetry. This residual bathymetry (Fig. 12b) is comparable to the residual basement maps of Müller et al. (2008a; their Fig. 11), with differences attributable to the isostatic corrections applied to sediment removal; and the predicted crustal (depth-to-basement) models OESbathy subjected to the same treatment as ETOPO1 provide a secondary check of our methodology (Fig. 13a). Removing sediments, including their loading, results in a difference map with deeper values than from ETOPO1 with the 
same sediment correction applied (compare Figs. 12a and 13a). This difference also appears in the residual OESbathy (Fig. 13b), which shows slightly negative mid-ocean ridges, mostly positive coastlines, and very negative terrigenous sediment fans.

\subsection{Bathymetric impacts on climate}

It remains unclear whether the differences between true and reconstructed bathymetry produce qualitatively important impacts on climate. One fundamental process for which bathymetry is potentially important is ocean tidal amplitude, which depends sensitively on basin resonances (which in turn depend sensitively on the ocean depth affecting the speed of gravity waves; Arbic et al., 2009). As noted above, both lateral (Krupitsky et al., 1996) and vertical (Sijp and England, 2005) ocean circulation have also been hypothesized to be sensitive to the details of bathymetry. Work to evaluate these sensitivities in modern models will be a future focus of research.

Another key issue concerns reconstructed paleobathymetry with simple vertical ocean margins, i.e., no realistic shelf-slope-rise structures, which if applied to paleo-oceans could result in substantially inaccurate paleoclimate simulations. The shelf-slope-rise structure is known to present-day ocean models but not for paleo-ocean models; the "modular" aspect of the OESbathy reconstruction provides a convenient means to test the effect of shelf-sloperise structures on modern climate simulations. Obviously, such a test could be undertaken by simply removing the actual shelf-slope-rise structures from ETOPO1, but to our knowledge this has never been done.

\section{Conclusions}

The reconstruction method described in this paper was applied to modern data in order to test how well simple parameterizations of the deep and coastal oceans replicate actual modern ocean bathymetry. Our method uses well-established oceanic crust ages, a cooling plate model, a parameterized sediment cover for the open oceans, and a parameterized shelf-slope-rise structure based on modern bathymetry of ocean margins. The reconstructed bathymetry is called "OESbathy".

Comparison of OESbathy with ETOPO1 shows globalscale agreement (Fig. 10; Table 3): OES average depth is $-3592 \pm 1668 \mathrm{~m}$ versus ETOPO1 average depth of $-3346 \pm$ $1772 \mathrm{~m}$, a $7.35 \%$ difference; OES median depth is $-4321 \mathrm{~m}$ versus ETOPO1 median depth of $-3841 \mathrm{~m}$. ETOPO1 is shallower, owing to seamounts and underwater plateaus (LIPs) that are not included in OESbathy. OESbathy maximum depth is $-6522 \mathrm{~m}$ versus ETOPO1 maximum depth of $-10714 \mathrm{~m}$, reflecting the absence of a full trench model in OESbathy. Significant differences also occur in complex coastal regions north of Siberia, the Falkland Islands, and Indonesia.

OES sediment thickness for the open oceans was parameterized as a multilayer sediment cover, with total thickness based on a third-order polynomial fit between the global ocean sediment thickness data of Divins (2003) and age of the underlying ocean crust. OES sediment thickness fits well to Divins' sediment thickness in the open oceans, but underestimates Divins' sediment thickness at greater ages, especially where terrigenous sediments have accumulated (e.g., Bay of Bengal, Amazon Fan).

The modeled shelf-slope-rise structure for connecting the reconstructed open ocean regions to the continental coastlines was parameterized with respect to adjacent ocean crust age and present-day geometry of the continental shelf-sloperise structure. The results show good fits to ETOPO1 for one half of the 64 profiles examined from around the world oceans; the other half of the profiles examined show moderate to poor fits to ETOPO1.

Residual ocean bathymetry computed from ETOPO1 consistently highlights positive anomalies in the North Atlantic, off the coast of southeast Africa, and the west Pacific Ocean, where actual bathymetry is elevated more than $1.5 \mathrm{~km}$ with respect to that produced by a cooling model of the oceanic lithosphere.

\section{The Supplement related to this article is available online at doi:10.5194/gmd-8-2735-2015-supplement.}

Acknowledgements. This work is part of the Open Earth Systems (OES) Project supported by the Frontiers in Earth System Dynamics Program of the US National Science Foundation, award EAR-1135382. We thank Dietmar Müller (EarthByte) for advice, Christopher R. Scotese (PALEOMAP) for PaleoAtlas data, and Evan Reynolds for technical help throughout the study. We would also like to thank Benjamin Hell and an anonymous referee for their many thoughtful comments that greatly improved our paper.

Edited by: N. Kirchner

\section{References}

Amante, C. and Eakins, B. W.: ETOPO1 1 arc-minute global relief model: procedures, data sources and analysis, US Department of Commerce, NOAA, National Environmental Satellite, Data, and Information Service, NGDC, Marine Geology and Geophysics Division, 2009.

Arbic, B. K., Karsten, R. H., and Garrett, C.: On tidal resonance in the global ocean and the back-effect of coastal tides upon open-ocean tides, Atmos. Ocean, 47, 239-266 doi:10.3137/OC311.2009, 2009. 
Célérier, B.: Paleobathymetry and geodynamics models for subsidence, Palaios, 3, 454-463, 1988.

Corti, G., Bonini, M., Conticelli, S., Innocenti, F., Manetti, P., and Sokoutis, D.: Analogue modelling of continental extension: a review focused on the relations between the patterns of deformation and the presence of magma, Earth-Sci. Rev., 63, 169-247, 2003.

Crosby, A., McKenzie, D., and Sclater, J.: The relationship between depth, age and gravity in the oceans, Geophys. J. Int., 166, 553573, 2006.

Crough, S. T.: The correction for sediment loading on the seafloor, J. Geophys. Res.-Sol. Ea., 88, 6449-6454, 1983.

Davison, I. and Underhill, J. R.: Tectonics and sedimentation in extensional rifts: Implications for petroleum systems, edited by: Gao, D., AAPG Mem. 100, 15-42, 2012.

Divins, D.: NGDC total sediment thickness of the world's oceans and marginal seas, NOAA, Boulder, CO, 2003.

Franke, D.: Rifting, lithosphere breakup and volcanism: Comparison of magma-poor and volcanic rifted margins, Mar. Petrol. Geol., 43, 63-87, 2013.

Hayes, D. E., Zhang, C., and Weissel, R. A.: Modeling paleobathymetry in the Southern Ocean, EOS, Transactions, 90, 165166, 2009.

Heine, C., Müller, R. D., and Gaina, C.: Reconstructing the lost eastern Tethys ocean basin: convergence history of the SE Asian margin and marine gateways, in: Continent-Ocean Interactions in Southeast Asia, edited by: Clift, P., Kuhnt, W., Wang, P., and Hayes, D., AGU Monograph, 149, 37-54, 2004.

Krupitsky, A., Kamenkovich, V. M., Naik, N., and Cane, M. A.: A Linear Equivalent Barotropic Model of the Antarctic Circumpolar Current with Realistic Coastlines and Bottom Topography, J. Phys. Oceanog., 26, 1803-1824, 1996.

Müller, R. D., Roest, W. R., Royer, J.-Y., Gahagan, L. M., and Sclater, J. G.: Digital isochrons of the world's ocean floor, J. Geophys. Res., 102, 3211-3214, 1997.

Müller, R. D., Sdrolias, M., Gaina, C., and Roest, W. R.: Age, spreading rates, and spreading asymmetry of the world's ocean crust: Geochem. Geophys. Geosys., 9, 1-19, 2008a.

Müller, R. D., Sdrolias, M., Gaina, C., Steinberger, B., and Heine, C.: Long-term sea-level fluctuations driven by ocean basin dynamics, Science, 319, 1357-1362, 2008b.

Parsons, B. and Sclater, J. G.: An analysis of the variation of ocean floor bathymetry and heat flow with age, J. Geophys. Res., 82, 803-827, 1977.
Peron-Pinvidic, G., Manatschal, G., and Osmundsen, P. T.: Structural comparison of archetypal Atlantic rifted margins: a review of observations and concepts, Mar. Petrol. Geol., 43, 21-47, 2013.

Scotese, C. R.: The PALEOMAP Project Paleo Atlas for ArcGIS, Volume 1, Cenozoic Paleogeographic and Plate Tectonic Reconstructions, PALEOMAP Project, Arlington, Texas, 2011.

Sijp, W. and England, M. H.: Role of Drake Passage in controlling the stability of the ocean's thermohaline circulation, J. Climate, 18, 1957-1966, 2005.

Simmons, H. L., Jayne, S. R., St. Laurent, L. C., and Weaver, A. J.: Tidally driven mixing in a numerical model of the ocean general circulation, Ocean Model., 6, 245-263, 2004.

Sclater, J. G., Hellinger, S., and Tapscott, C.: The paleobathymetry of the Atlantic Ocean from the Jurassic to the present, J. Geol., 85, 509-552, 1977a.

Sclater, J. G., Abbott, D., and Thiede, J.: Chapter 2: Paleobathymetry and sediments of the Indian Ocean, in Indian Ocean Geology and Biostratigraphy, edited by: Heirtzler, J. R., Bolli, H. M., Davies, T. A., Saunders, J. B., and Sclater, J. H., Special Publications, American Geophysical Union, Washington DC, 25-59, $1977 b$.

Sykes, T. J.: A correction for sediment load upon the ocean floor: Uniform versus varying sediment density estimations - Implications for isostatic correction, Mar. Geol., 133, 35-49, 1996.

Turcotte, D. L. and Schubert, G.: Geodynamics, 2nd Edn., Cambridge University Press, 848 pp., 2014.

Watts, A., Rodger, M., Peirce, C., Greenroyd, C., and Hobbs, R.: Seismic structure, gravity anomalies, and flexure of the Amazon continental margin, NE Brazil, J. Geophys.-Res. Sol. Earth, 114, 1-23, 2009.

Whittaker, J. M., Goncharov, A., Williams, S. E., Müller, R. D., and Leitchenkov, G.: Global sediment thickness data set updated for the Australian-Antarctic Southern Ocean, Geochem. Geophy. Geosys., 14, 3297-3305, 2013.

Wright, J. D. and Miller, K. G.: Control of North Atlantic Deep Water circulation by the Greenland-Scotland Ridge, Paleoceanography, 11, 157-170, 1996.

Xu, X. Q., Lithgow-Bertelloni, C., and Conrad, C.P.: Global reconstructions of Cenozoic seafloor ages: Implications for bathymetry and sea level, Earth Planet. Sci. Lett., 243, 552-564, 2006.

Ziegler, P. A. and Cloetingh, S.: Dynamic processes controlling evolution of rifted basins, Earth-Sci. Rev., 64, 1-50, 2004. 